\title{
Intervening Negative Impact of Stigma on Employability of a Person with Schizophrenia Through Social Case Work
}

\author{
Kamlesh Kumar Sahu'
}

Received: 15 March 2015/Accepted: 25 June 2015/Published online: 8 July 2015

(C) Springer India Pvt. Ltd. 2015

\begin{abstract}
Schizophrenia impose a heavy toll on a person's capacity to work, there are serious barriers to employment that mental health service users have to overcome some of them within mental health service themselves, stigma and discrimination from employers and the general public, having basis as their implicit assumption regarding employability of people with mental health problems. This is an outcome study based on single case design methodology which assessed the efficacy of social case work (intervention). It provides evidence that a person with schizophrenia can achieve and maintain successful employment with adequate social case work intervention despite the challenges like stigma imposed by this serious mental illness.
\end{abstract}

Keywords Employability - Vocational rehabilitation . Stigma $\cdot$ Schizophrenia $\cdot$ Social case work

\section{Introduction}

Schizophrenia is a devastating, chronic, severe, and disabling brain disorder affects socio-occupational functioning capabilities of individual in daily life such as self-care, communication, interpersonal relationships, family, social, and occupational area. It is the third most debilitating mental illness with a prevalence of $0.4 \%$ [1], accounting for $1.1 \%$ of the total disability-adjusted life years

Kamlesh Kumar Sahu

withkamlesh@gmail.com

1 Department of Psychiatric Social Work, Institute of Psychiatry (IPGME\&R, SSKM Hospital), 7 D.L. Khan Road, Kolkata 700025, India
(DALY's), and $2.8 \%$ of the years lost due to disability (YLD's) as per the global burden of disease [2]. Although it is an illness with a poor prognosis [3] about one-fourth of the persons affected with it fully recover after one or more episodes, in rest three fourth of the cases the disturbance takes a chronic form; half of this group exhibits negative symptoms (flattened affect, poverty of thought and speech, apathy, loss of interest, social withdrawal, and motor retardation), the remaining half have long-lasting positive symptoms such as delusions and hallucinations. As a result, people with schizophrenia or serious mental illnesses are more likely to be unemployed or to be underemployed in inferior positions that are incommensurate with their skills or training. If they return to work following an illness, they often face hostility and reduced responsibilities [4].

Employment is not an impossible goal for persons with schizophrenia. Studies show a clear interest in work and employment activities among users of psychiatric services, with up to $90 \%$ of users wishing to go into (or back to) work. Though, for people with long term mental illness, rates of employment are low [5, 6], mental health symptoms and greater perceived obstacles (e.g., stigma, fear of failure, and insufficient skills) were significant contributors to lived difficulty in pursuing work [7] elements of selfstigma-feelings of loss of self-esteem and dignity, hopelessness, fear, shame, guilt, etc' associated with mental illness or schizophrenia [8] has very negative influence on efforts to resume work after recovery from the illness [9, 10]. Discriminating attitudes of employers [11-13], an inappropriate or unsuitable service approach, [5] lack of supportive work environment [12] and structures of social welfare [14] are other obstacles in finding and retaining an employment.

Various studies indicate that successful employment would have a positive impact on other areas such as 
symptom reduction, community integration, and improved functioning [15-18]. Employment reintegrates people back into the community, provides an independent income and a sense of identity, and fills an empty day with purpose and activity. Unpaid voluntary work can also help to fulfil this role [19]. Employment, work, and leisure are key dimensions of social adjustment. Being 'in work' has important implications for the personal well-being, social status and civil rights of those with schizophrenia or mental illness [20]. Evidence suggests that employment reduces stigma toward people recovering from schizophrenia [21, 22].

Stigma is a social process or related experience characterized by exclusion, rejection, blame or devaluation that results from an adverse social judgment about a person or group [23] based on attribute, trait or disorder that makes an individual as being unacceptably different from the normal people with whom he or she routinely interacts. Wide range medical conditions are stigmatized e.g. leprosy [24], cancer [25], mental illness [26-28] and epilepsy [29, 30]. Stigmatization occurs on societal, interpersonal, and individual levels [31]. Numerous studies have shown that stigma has detrimental consequences for the psychological well-being of stigmatized individuals $[32,33]$. Stigmatized individuals can attempt to mitigate the negative psychological and social impact of stigmatization (e.g. depression, anxiety, isolation, reduced social network, limited social support) by employing a variety of coping strategies [31].

Social case work is "a process........ to help individuals to cope more effectively in their problems in social functioning" $[34,35]$. It is a primary method of Social Work is concerned with the adjustment and development of individual towards more satisfying human relations. It is one of the direct methods of social work which uses the case-by-case approach for dealing with individuals or families as regards their problems of social functioning. Case work aims at individualized services in the field of social work. Casework method based on systematic and orderly practice experiences which include a process of intake, social study and diagnosis, treatment, termination and follow-up towards problem solution and social functioning among individuals [36]. Various therapies and interventions can be part of social case work based on the needs and suggestibility of the case. There are various approaches and models in social work practice which also implies in psychiatric setting, one of the approach is strength-based approaches. Which generally conceptualize strengths in two distinct ways-First, assets, resources, and abilities can be used to assist in helping an adult to continue to develop. Accordingly, strengths are used as building blocks for service planning and program development. Second, strengths can be developed or enhanced. Consequently, changes in the availability of various assets, resources, and abilities for an individual can be viewed as a service delivery outcome. The strengthsbased approach to case management with people with severe mental illness is well established. In the present case work, predominately strength-based approach was used [37-39].

In India at least $6.5 \%$ of the Indian population have some form of mental disorders [40], severe mental disorders in India that include schizophrenia, bipolar disorder, organic psychosis and major depression affect nearly 20 per 1000 population [41] prevalence of mental disorders range from 18 to 207 per 1000 population with the median 65.4 per 1000 at any given time. Against the huge need for mental health services mental health facility and trained manpower is insufficiency and centered in urban areas, as a result, there is over case loaded on mental health facilities [42-45]. Most of these persons with mental illness live in rural areas, far away from any modern mental health facilities [46]. Stigma, lack of knowledge on the treatment availability and potential benefits of seeking treatment is a big barrier to access mental health service [19]. Mental health practice relies heavily on the pharmacological treatment while community participation and psychosocial approaches remain unrealized. Very limited psychosocial treatment services availability in the country [47]. In India psychiatric OPDs are generally overburdened with large no of cases and there is very less social work or psychosocial services available and moreover there is very less awareness about this kind of services and its possible usefulness among professionals. The majority of the persons with mental illness reside in their own house, require help to modify immediate family's attitude followed by friends and neighbours attitudes towards them. This can be address through social case work intervention.

So this piece of publication may contribute to intervene the situation and also to demonstrate efficacy of social case work services $[36,50]$ which is very rare in mental health or psychosocial services even though good number of social workers are practicing in this field.

\section{Methodology}

A single case design methodology [48] was adopted in order to make an empirical in-depth inquiry about a contemporary phenomenon of stigma and employability in a person recovering from schizophrenia. Case study research is a good fit with many forms of social work practice [49] used widely by Psychiatric Social Workers [50-53] and other mental health professional as well [54-56]. The case study has great potential for building social work knowledge for assessment, intervention, and outcome [49]. 


\section{Assessments}

\section{Case Introduction}

Index client Mr. PSS 29 years old, unmarried, male, hailing from a middle-class nuclear Hindu family from a semiurban area located in outskirts of a metropolitan city of India. He completed higher secondary then diploma in civil engineering.

This case was selected for reporting for two reasons first the case was completed social case work services with good compliance and positive outcome which is not very common is such setting with such diagnosis particularly when there is lack of psychosocial intervention. The department was newly opened so to demonstrate the scope and possible outcome of the social case work intervention case were recruited for presentation.

\section{Sources of Information}

The client himself, his father, and case record file were sources of information which were reliable and adequate.

\section{The Reason for Referral}

He was referred to the Department of Psychiatric Social Work of a tertiary care teaching institution for vocational rehabilitation on December 2011.

\section{Brief Clinical History}

Since the client was already diagnosed at psychiatric Out Patient Department (OPD) so detail clinical assessment was not done instead of specific psychosocial assessment was done. The client was diagnosed as having Schizophrenia he has been suffering from last 2 years and 8 months (since April 2009) predisposed by uncongenial home environment with nil contributory personal and past history but having family history (see Fig. 1) of Schizophrenia in mother, psychotic illness in maternal grandmother and one maternal aunt and Obsessive Compulsive Disorder (OCD) in younger sister. He has been under treatment of the Department of Psychology since last 4 months and under the Department of Psychiatry since last 2 and half years in the same institution. At the time of referral he was on regular medicine and was improving with medication, positive symptoms were controlled but he was jobless and some negative symptoms continuing (see Table 1).

Social and family analysis reveals (see Fig. 1) that low level of awareness about illness, high stigma perceived by client (see Table 2) and family, high degree of negative expressed emotion in terms of dissatisfaction, poor family function in terms of poor communication, reinforcement and adaptive patterns. Client's illness has imposed huge perceived burden on the family since his mother's illness and younger sister's illness has a negative impact on the family. Though the mother was managing her job in post office and sister is married and settled in another city but her husband has personality disorder so they have adjustment problem which gives consistent trouble to this family. Father is trying to deal with all these but at the time perceived high burden. As a consequence of all these socio-economic function of the family was affected.

Till December 2011 (at the time of referral), he had changed at least three jobs each time he had almost similar complaints of adjustment problems with the job hours and colleagues. He himself and treating psychiatrist felt he con not work even though they felt that work had a very important role not only for his socio-occupational life but also to recover fully from schizophrenia. It was also evident that he has been on regular psychiatric treatment and had fluctuation in symptoms whenever he felt better for some time, joint a job but after joining he had similar problem so he had to leave. He uses to feel very much stigmatized (see Table 2; Fig. 3), at the time blamed God or own luck for the illness and try to keep isolated him from other. Sometimes he used to feel tired without doing any work. Keeping all these sometimes, he had difficulties in sustaining motivation for work and selfsteam. He was found irregular in daily routine e.g. getting up very late, doing nothing hours in a day having minimal interaction with others and not participating in any social event. He was doing a volunteer job in a contraction company but was very irregular. He uses to think he should not work or go out until getting well. At times, he felt because he is taking medicines he was not fit for any work. Even his father supported his views on this and told him several times not to worry about the job; he ensured that without working also he will get sufficient money for his needs. Whenever anyone asked anything or commented negatively about his work he uses to take very negatively and felt because of his illness he was treated like that. All these could be explained by negative symptoms and disengagement coping (e.g., avoidance) to deal with stigma.

\section{Interventions}

\section{Strength and Focus of Intervention}

It was very evident that the client had a technical qualification (diploma in civil engineering), well-adjusted work 
Fig. 1 Genogram. Most of the family members in this family are educated up to secondary level. Men works in factory, agricultural work or having small business women are house wife

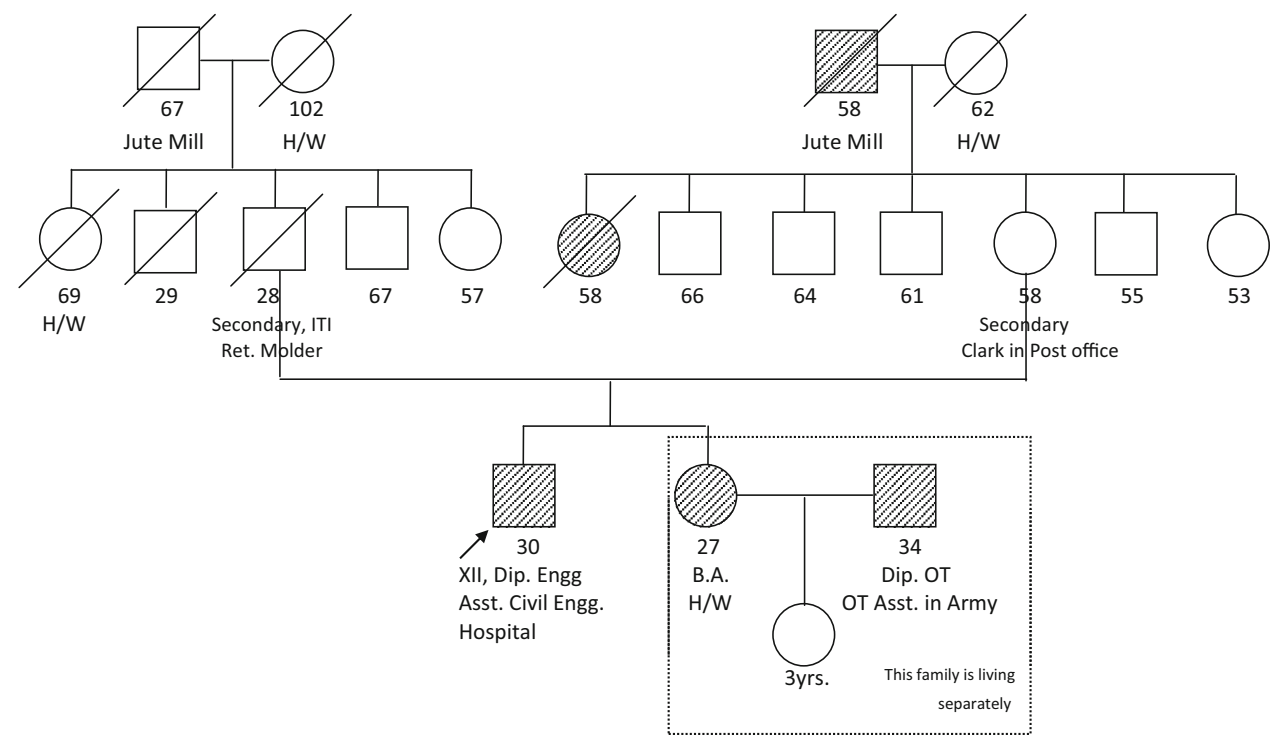

\section{Interventions Plan}

All intervention was done as OPD basis, initially biweekly session lasting around 45-60 min then monthly and subsequently once in 3 months held. The majority of the sessions were individual with the client, few sessions were conducted jointly with father, few sessions with father and mother separately, and two sessions with sister.

Interventions consisted of:

Rapport building
Psychoeducation
Stigma alleviation
Activity scheduling
Vocational counselling
Pre-work behaviour training
Job skills training
Family intervention
Consistent monitoring
Follow up and support through phone

\section{Rapport Building}

Establishing rapport and to obtain client's faith and confidence on therapeutic process was the first task which was achieved by active listening and reassuring and other supportive measures. Once the client's trust was gained he becomes co-operative and ready to receive treatment.

\section{Psychoeducation}

Case worker started with a psychoeducation to the client and his father about the illness (nature, causes, course, 
Table 1 Positive and negative syndrome

\begin{tabular}{|c|c|c|c|}
\hline & Positive scale & Pre intervention score & Post intervention score \\
\hline P1 & Delusions & 3 & 2 \\
\hline $\mathrm{P} 2$ & Conceptual disorganization & 2 & 2 \\
\hline P3 & Hallucination behavior & 3 & 2 \\
\hline P4 & Excitement & 3 & 2 \\
\hline P5 & Grandiosity & 1 & 1 \\
\hline P6 & Suspicious/persecution & 4 & 2 \\
\hline \multirow[t]{3}{*}{ P7 } & Hostility & 3 & 2 \\
\hline & Total (ranges are 7-49) & 19 & 13 \\
\hline & Negative scale & & \\
\hline N1 & Blunted affect & 4 & 2 \\
\hline $\mathrm{N} 2$ & Emotional withdrawal & 4 & 2 \\
\hline N3 & Poor rapport & 3 & 2 \\
\hline N4 & Passive/apathetic social withdrawal & 5 & 2 \\
\hline N5 & Difficulty in abstract thinking & 3 & 2 \\
\hline N6 & Lack of spontaneity & 4 & 2 \\
\hline \multirow[t]{3}{*}{ N7 } & Stereotyped thinking & 5 & 2 \\
\hline & Total (ranges are $7-49$ ) & 28 & 14 \\
\hline & General psychopathology scale (G) & & \\
\hline G1 & Somatic concern & 1 & 1 \\
\hline $\mathrm{G} 2$ & Anxiety & 4 & 2 \\
\hline G3 & Guilty feeling & 5 & 2 \\
\hline G4 & Tension & 5 & 2 \\
\hline G5 & Mannerism and posturing & 3 & 2 \\
\hline G6 & Depression & 4 & 2 \\
\hline G7 & Motor retardation & 3 & 2 \\
\hline G8 & Uncooperativeness & 1 & 1 \\
\hline G9 & Unusual thought content & 3 & 2 \\
\hline G10 & Disorientation & 1 & 1 \\
\hline G11 & Poor attention & 3 & 1 \\
\hline G12 & Lack of judgment and insight & 1 & 1 \\
\hline G13 & Disturbance of violation & 3 & 2 \\
\hline G14 & Poor impulse control & 1 & 1 \\
\hline G15 & Preoccupation & 4 & 2 \\
\hline \multirow[t]{3}{*}{ G16 } & Active social avoidance & 4 & 2 \\
\hline & Total score (ranges are 16-112) & 46 & 26 \\
\hline & PANSS sum score & 93 & 53 \\
\hline
\end{tabular}

Table 2 Internalized stigma

\begin{tabular}{llll}
\hline S. no. & Subscales & Before intervention & After intervention \\
\hline 1 & Alienation & 3.66 & 2.00 \\
2 & Stereotype endorsement & 3.85 & 1.85 \\
3 & Discrimination experience & 3.60 & 1.80 \\
4 & Social withdrawal & 3.16 & 1.41 \\
5 & Stigma resistance & 3.80 & 2.00 \\
& Total Score & 3.69 & 1.86 \\
\hline
\end{tabular}

Interpretation of scores 1.00-2.00 minimal to no internalized stigma, 2.01-2.50 mild internalized stigma, 2.51-3.00 moderate internalized stigma, 3.01-4.00 severe internalized stigma 
treatment, prognosis), need and importance of the psychosocial rehabilitation services and off course their role on it; to make them understand that in this phase of illness they need something more than the medication and their role (willingness, efforts and participation or practice) is very important. He was explained the possible causes of illness to intervene faulty attribution or misconception about it and prevalence of the illness in order normalization of the sufferings by this illness. The role of genetic inheritance in the manifestation of the illness was also explained. This increased understanding and awareness about the illness and problem-related to that in the family and eventually lend a hand in reducing stigma.

\section{Stigma Alleviation}

Effective strategies for addressing self-stigma include motivational interviewing, ringing a bell on the client's own strengths, and conveying positive stories of people with schizophrenia. The Clint was also taught secondary control coping: distraction and acceptance. He was motivated to keep himself engage in various activities like watching a favourite television program, reading the news paper, going through some civil designing work which he did earlier etc. to deal with the stress of stigma.

\section{Activity Scheduling}

Subsequently activity scheduling was done which includes a structure of day to day activities, which was guided and monitored by the case worker with the help of father. Checklist and model activity schedule was used which helped to restore the disturbed daily routine of the client.

\section{Vocational Counselling}

Once the client started maintaining regular daily routine then he was provided vocational counselling in order to involve him/her some productive activity, he was encouraged to be regular and punctual in his volunteer work (which he was doing in a civil construction firm) in a stepwise manner over a period of 4 weeks.

\section{Pre-work Behaviour and Job Skills Training}

His pre-work behaviour was analyzed and deficit areas were addressed. Once he was able to work 3-5 days in a week, he was encouraged to negotiate for remuneration from the employers (for volunteer work) which was successfully achieved and later on he was observed as a full-time employee in the same company for 1 year tenure in spite of not recommended by his treating psychiatrist since he felt the client could not take his job stress and might get deteriorated.

\section{Family Intervention}

Session with the father was helpful in enhancing communication pattern positively and decreasing negative expressed emotion in terms of dissatisfaction. He was also thought to adaptive coping strategies which involve confronting problems directly, making reasonably realistic appraisals of problems, recognizing and changing unhealthy emotional reactions. By achieving this he learnt to cope up in a better way with multiple family problems and issues. The client's father was pursued to seek help for other family members who were having mental health problem which was successful. The client's mother was already in OPD treatment for schizophrenia, so adequate psychosocial intervention was provided and to some extent she improved and get back to her service which has remarkable impact on reducing family burden and also had positive impact on the client (Later on Client's sister and brother in law were also started taking treatment for the same institute). Reinforcement practice was nil or nominal in the family so it was addressed and encourage to practice reinforcement e.g., appreciating for small-small achievements, greetings etc. Whenever required.

\section{Consistent Monitoring, Follow Up and Support through Phone}

He was closely monitored and consistently helped for upcoming problems in each visit to the institute e.g. once he had urinary incontinence (involuntary excretion of urine), erectile dysfunction, drugs change by the new doctors etc. He was also given a contact number to be in constant touch and report or sick help whenever needed which has given much feeling of assurance to the client.

\section{Outcome}

He had shown improvement in most of the areas e.g. client's severe internalized stigma reduced to minimal to no internalized stigma level on post intervention assessment using Internalized Stigma of Mental Illness Inventory (see Table 2; Fig. 3) [57]; symptoms particularly negative symptoms had also reduced significantly on post assessment using Positive and Negative Syndrome Scale (PANSS) (see Table 1; Fig. 2) [58]. During the course of intervention he was on routine psychiatric treatment mostly with good compliance and he also took therapy sessions in psychology department so definitely that had very positive impact on symptom control. Client's self-esteem, confidence level had also an improvement. In the family level stigma, perceived family burden, negative expressed emotion in terms of dissatisfaction, poor family function in terms of poor 
Fig. 2 Positive and negative syndrome scale

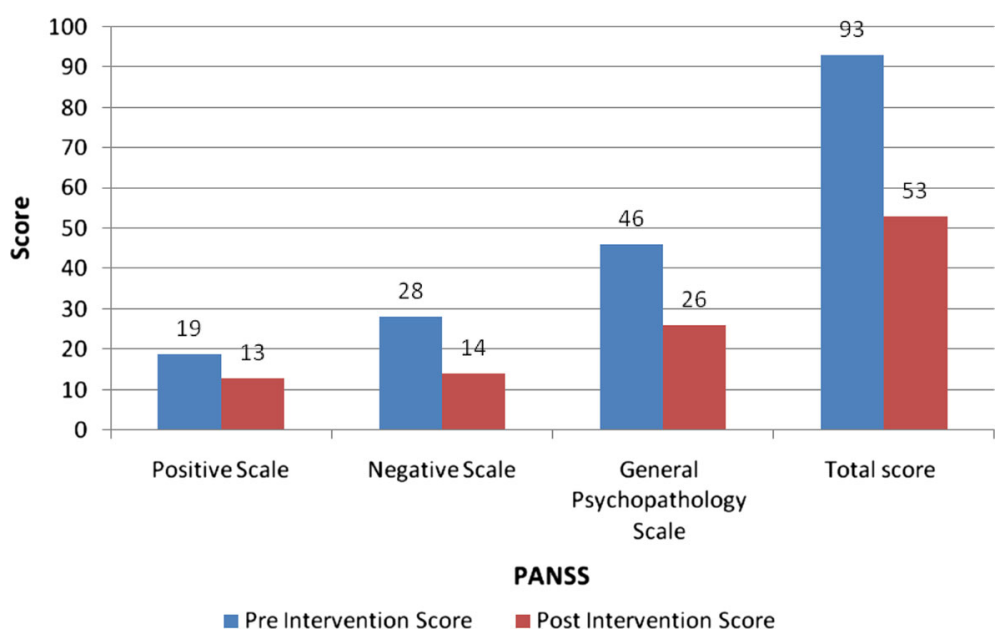

functioning), environmental factors (societal and cultural influence, local economy, labor laws, disability policies, and governmental regulations), and interventions are barriers to employment of persons with schizophrenia $[59,60]$ but those factors have not studied in the present study. In the present case, an individual is having high internalized stigma since he is suffering from a medical condition schizophrenia which is stigmatized with a wide range of other medical conditions [24-30]. Stigma is powerful and discrediting social label that radically changes the way individuals view themselves and are viewed as persons in society [60-65]. Stigma can be felt (anticipated or internal), leading to an unwillingness to seek help and access to resources. There is an increasing interest in the benefits of conceptualizing prejudice and discrimination as stressors in the lives of stigmatized people [66-68]. The core feature of stigma is that a stigmatized person has an attribute that conveys a devalued social identity within a particular context [69]. This devaluation leads to a variety of stressors. A stressor is an event in which environmental or internal demands heavy toll or goes beyond the adaptive capacity of the individual [70]. Prejudice can increase environmental demands by affecting access to educational and employment opportunities, confining stigmatized people to the lower rungs of the socioeconomic ladder, and affecting the quantity and quality of health care stigmatized people receive [66].

In this case, the client had disengagement coping style to cope up with the stressor, along with negative symptoms of schizophrenia made him totally isolate and disengaged to social activities. Teaching him engagement coping in the form of secondary control coping strategies helped him to confront stigma stressor. Engagement coping can be distinguished by whether it is aimed at gaining primary or secondary control over the stressful event. Primary-control coping involves changing the stressful situation (by
Apart from stigma there are number factors: patient characteristics (clinical problems, including symptoms of schizophrenia and poorer neurocognitive and intrapsychic 
controlling the situation or the self in the situation), whereas secondary control coping involves adapting to the stressful event. A great deal of the research on stigma has focused on secondary control coping (distraction, cognitive restructuring, and acceptance) strategies through which stigmatized people can psychologically adapt to the stigma-related stressors that confront them [68]. Distraction involves engaging in cognitions or behaviours that draw attention away from the stressor.

Again, in the present case the client has having good employability which was major strength but high internalized stigma was barrier to vocational functioning [66] after intervention he got paid employment which has been observed an important way to reduce stigma and ways of integration and recovery $[22,71,72]$.

\section{Conclusion}

This social case work report is evidence that with an adequate psychosocial intervention adjoined with pharmacological treatment to a person with schizophrenia can successfully achieve and maintains employment despite the challenges like self-stigma presented by schizophrenia.

Acknowledgments It's an academic study done with no funding support from any where

Conflict of interest I have no conflict of interest

\section{References}

1. Jenkins R, Bebbington P, Brugha T. British psychiatric morbidity survey. Br J Psychiatry. 1998;173:4-7.

2. World Health Report. Mental health: new understanding, new hope. Geneva: World Health Organization, 2001. Available from: www.who.int/whr/2001/en/whr01_en.pdf. Accessed 2 May 2015

3. Sawa A, Snyder S. Schizophrenia: diverse approach to complex disease. Science. 2002;296:692-5.

4. Stuart H. Stigma and work. Healthc Pap. 2004;5(2):100-11.

5. Boardman J, Grove B, Perkins R, Shepard G. Work and employment for people with psychiatric disabilities. Br J Psychiatry. 2003;182:467-8.

6. Marwaha S, Johnson S. Schizophrenia and employment-a review. Soc Psychiatry Psychiatr Epidemiol. 2004;39(5):337-49.

7. Huxley P, Thornicroft G. Social inclusion, social quality and mental illness. Br J Psychiatry. 2003;182:289-90.

8. Van Brakel WH. Measuring health-related stigma-a literature review. Psychol Health Med. 2006;11:307-34.

9. Shrivastava A, Johnston ME, Thakar M, Shrivastava S, Sarkhel G, Sunita I, et al. Origin and impact of stigma and discrimination in schizophrenia-patients' perception: Mumbai study. Stigma Res Act. 2011;1:67-72.

10. Lai YM, Hong CPH, Chee CYI. Stigma of mental illness. Singap Med J. 2000;42(3):111-4.

11. Mangili E, Buizza C, Rossi G. Attitudes toward disabilities and mental illness in work settings: a review (in Italian). Epidemiol Psichiatr Soc. 2004;13(1):29-46.
12. Mercer William M. mercer/foster higgins national survey of employer-sponsored health plans 1998. New York: William M. Mercer; 1999.

13. Scheid TL. The Americans with disabilities act: mental disability and employment practices. J Behav Health Serv Res. 1998;25(3):312-24.

14. McDaid D, Claire C, Martin K. Promoting mental well-being in the workplace: a European policy perspective. Int Rev Psychiatry. 2005;17(5):365-73.

15. Arns PG, Linney JA. Work, self, and life satisfaction for persons with severe and persistent mental disorders. Psychosoc Rehabil J. 1993;17:63-79.

16. Bell MD, Milstein RM, Lysaker PH. Pay as an incentive in work participation by patients with severe mental illness. Hosp Community Psychiatry. 1993;44:684-6.

17. Drake RE, Becker DR, Biesanz JC, Torrey WC, McHugo GJ, Wyzik PF. Partial hospitalization vs. supported employment: 1 . vocational outcomes. Community Ment Health J. 1994;30: 519-32.

18. Lysaker P, Bell M. Work rehabilitation and Improvements in insight in schizophrenia. J Nerv Ment Dis. 1995;183:103-6.

19. Crosse C. A meaningful day: integrating psychosocial rehabilitation into community treatment of schizophrenia. Med J Aust. 2003;178:S76-8.

20. Mueser KT, Becker DR, Torrey WC, Xie H, Bond GR, Drake $\mathrm{RE}$, et al. Work and non-vocational domains of functioning I persons with sever mental illness? J Nerv Ment Dis. 1997;185: 419-26.

21. van Zelst C. Stigmatization as an environmental risk in schizophrenia: a user perspective. Schizophr Bull. 2009;35(2): 293-6.

22. Perkins DV, Raines JA, Tschopp MK, Warner TC. Gainful employment reduces stigma toward people recovering from schizophrenia. Community Ment Health J. 2009;45(3):158-62.

23. Weiss M, Ramakrishna J, Somma D. Health-related stigma: rethinking concepts and interventions 1. Psychol Health Med. 2006;11(3):277-87.

24. Opala J, Boillot F. Leprosy among the limba: illness and healing in the context of world view. Soc Sci Med. 1996;42(1):3-19.

25 . Fife B, Wright E. The dimensionality of stigma: a comparison of its impact on the self of persons with HIV/AIDS and cancer. J Health Soc Behav. 2000;41(1):50.

26. Angermeyer $M$, Matschinger $H$. Lay beliefs about schizophrenic disorder: the results of a population survey in Germany. Acta Psychiatr Scand. 1994;89(s382):39-45.

27. Corrigan P, Penn D. Lessons from social psychology on discrediting psychiatric stigma. Am Psychol. 1999;54(9):765-76.

28. Thara R, Srinivasan T. How stigmatising is schizophrenia in India? Int J Soc Psychiatry. 2000;46(2):135-41.

29. Pasternak J. An analysis of social perceptions of epilepsy: increasing rationalization as seen through the theories of Comte and Weber. Soc Sci Med Part E. 1981;15(3):223-9.

30. Sahu KK, Pillai RR, Hazra S, Verma AN. Stigma experienced by primary care givers of persons with Epilepsy. Natl J Prof Soc Work. 2009;10(1\& 2):17-33.

31. Bos A, Pryor J, Reeder G, Stutterheim S. Stigma: advances in theory and research. Basic Appl Soc Psychol. 2013;35(1):1-9.

32. Meyer I. Prejudice, social stress, and mental health in lesbian, gay, and bisexual populations: conceptual issues and research evidence. Psychol Bull. 2003;129(5):674-97.

33. Stutterheim S, Pryor J, Bos A, Hoogendijk R, Muris P, Schaalma H. HIV-related stigma and psychological distress: the harmful effects of specific stigma manifestations in various social settings. AIDS. 2009;23(17):2353-7.

34. Perlman HH. Social casework: a problem-solving process. Chicago: University of Chicago Press. 1957. 
35. Perlman HH. Social casework as problem solving process. Deutsche Krankenpflegezeitschrift. 1975;28(4):193.

36. Sahu KK. Social casework practice in psychiatric setting in India. Dysphrenia. 2013;4:146-7. Available from: http://dysphrenia. hpage.co.in/guest-editorial-social-casework-practice-in-psychiatricsetting-in-india-fulltext_6358933.html. Accessed 2 May 2015

37. Chapin R, Cox EO. Changing the paradigm: strengths-based and empowerment oriented social work with frail elders. Gerontol Soc Work Pract. 2001;36:165-79.

38. Rapp CA, Pettus CA, Goscha RJ. Principles of strengths-based policy. J Policy Pract. 2006;5(4):3-18.

39. Sandra P. Hirst RN Annette M. Lane Carol-Lynne Le Navenec RN. Strength-based approaches for mental wellness in seniors and adults with disabilities. Alberta Health Services-Addiction and Mental Health 2011. Available from: http://www.alberta healthservices.ca/assets/info/res/mhr/if-res-mhr-strength-basedapproach.pdf.

40. National Commission on Macroeconomics and Health. Burden of disease in India (Background Papers), New Delhi: Ministry of Health and Family Welfare. Available from: http://www.who.int/ macrohealth/action/NCMH-Burden\%20of\%20disease-(29\%20Sep \%202005).pdf (2005). Accessed 24 May 2012

41. National Portal Government of India. Mental Health Programme. Available from: http://india.gov.in/sectors/health_family/mental_ health.php. Accessed 24 May 2012.

42. Gururaj G, Girish N, Isaac MK. Mental, neurological and substance abuse disorders: strategies to- wards a systems approach. National Commission on Macroeconomics and Health Background Papers-Burden of Disease in India. New Delhi: Ministry of Health \& Family Welfare; 2005.

43. NHRC, Government of India. Quality Assurance in Mental Health. New Delhi: National Human Right Commission; 1999.

44. Sahu KK, Sahu S. Rural mental health in India. Disphrenia. 2013;4(1):7-11. Available from: http://dysphrenia.hpage.co.in/ article_rural_mental_health_in_india_fulltext_11959459.html. Accessed 2 May 2015

45. Ganguly O, Sahu KK, Mukhopadhyay, S. Outcome study of disability management for persons with schizophrenia living in the community [M.Phil.]. Kolkata: West Bengal University of Health Sciences;2014.

46. National Mental Health Programme for India. New Delhi: Ministry of Health and Family Welfare; 1982.

47. Hazra S, Sahu KK, Pillai RR. Psychosocial rehabilitation needs of persons with mental illness in Jharkhand. RINPAS J. 2012;4(1):77-80.

48. Yin R. Case study research. Thousand Oaks: Sage Publications; 2003.

49. Gilgun JF. A case for case studies in social work research. Soc Work. 1994;39(4):37.

50. Sahu KK. Family intervention with a case of bipolar I disorder with family conflict. Dysphrenia. 2013;4:165-71. Available from: http://dysphrenia.hpage.co.in/case-report-family-interventionwith-a-case-of-bipolar-i-disorder-with-family-conflict-fulltext_ 53331379.html. Accessed 2 May 2015

51. Jagannathan A, Sekar K, Janardhan Reddy YC. A casework report of social anxiety disorder with anankastic personality disorder: a cognitive behaviour therapy approach. Dysphrenia. 2013;4(2):158-64.

52. Baruah U, Hamza A. A social casework report of adolescent adjustment disorder with borderline intelligence. Dysphrenia. 2013;4(2):148-57.

53. Ganguly O, Sahu KK. Psychosocial management and rehabilitation of a person with moderate intellectual disability. In: Proceedings of ICCD, Kolkata; 2014, pp 77-82.
54. Clare L, Wilson B, Carter G, Hodges J. Cognitive rehabilitation as a component of early intervention in Alzheimer's disease: a single case study. Aging Ment Health. 2003;7(1):15-21.

55. Lysaker P, Davis L, Eckert G, Strasburger A, Hunter N, Buck K. Changes in narrative structure and content in schizophrenia in long term individual psychotherapy: a single case study. Clin Psychol Psychother. 2005;12(5):406-16.

56. Lysaker P, Buck K, Ringer J. The recovery of metacognitive capacity in schizophrenia across 32 months of individual psychotherapy: a case study. Psychotherapy Res. 2007;17(6):713-20.

57. Ritsher JB, Otilingam PO, Grajales M. Internalized stigma of mental illness: psychometric properties of a new measure. Psychiatry Res 2003;121:31-49. http://www.repositories.cdlib.org/ postprints/2005.

58. Kay SR, Fiszbein A, Opler LA. The positive and negative syndrome scale (PANSS) for schizophrenia. Schizophr Bull. 1987; 13:261-76.

59. Rosenheck R, Leslie D, Keefe R, Mcevoy J, Swartz M, Perkins D, Lieberman J. Barriers to employment for people with schizophrenia. Am J Psychiatry. 2006;163(3):411-7.

60. Bond GR, Drake RE. Predictors of competitive employment among patients with schizophrenia. Curr Opin Psychiatry. 2008; 21(4):362-9.

61. Goffman E. Stigma: notes on the management of spoiled identity. Garden City: Anchor Books; 1963.

62. Holzemer W, Uys L, Makoae L, Stewart A, Phetlhu R, Dlamini P, et al. A conceptual model of HIV/AIDS stigma from five African countries. J Adv Nurs. 2007;58(6):541-51.

63. Link BG, Phelan JC. Conceptualizing stigma. Annu Rev Sociol. 2001;27:363-85.

64. Petro G, Airhihenbuwa CO, Simbayi L, Ramlagan S, Brown B. HIV/AIDS and 'othering' in South Africa: the blame goes on. Cult Health Sex. 2006;8(1):67-77.

65. Visser M, Makin J, Vandormael A, Sikkema K, Forsyth B. HIV/ AIDS stigma in a South African community. AIDS Care. 2009;21(2):197-206.

66. Allison KW. Stress and oppressed category membership. In: Swim J, Stangor C, editors. Prejudice: he target's perspective. San Diego: Academic Press; 1998. p. 145-70.

67. Clark R, Anderson N, Clark V, Williams D. Racism as a stressor for African Americans: a biopsychosocial model. Am Psychol. 1999;54(10):805-16.

68. Miller CT, Major B. Coping with stigma and prejudice. In: Heatherton $\mathrm{T}$, editor. The social psychology of stigma. New York: Guilford Press; 2000. p. 243-72.

69. Crocker J, Major B, Steele C. Social stigma. In: Gilbert D, Fiske S, Lindzey G, editors. The handbook of social psychology. 4th ed. Boston: McGraw-Hill; 1998. p. 504-53.

70. Lazarus R, Folkman S. Stress, appraisal, and coping. New York: Springer Pub. Co.; 1984.

71. Yanos PT, Lysaker PH, Roe D. Internalized stigma as a barrier to improvement in vocational functioning among people with schizophrenia-spectrum disorders. Psychiatry Res. 2010;178(1): 211-3.

72. Brohan E, Elgie R, Sartorius N, Thornicroft G. GAMIAN-Europe Study Group. Self-stigma, empowerment and perceived discrimination among people with schizophrenia in 14 European countries: the GAMIAN-Europe study. Schizophr Res. 2010; 122(1):232-8. 